Research

Open Access

\title{
Effect of Poly Phenols in Enhancing the Swimming Capacity of Rats
}

\section{Mahadevappa Siddalinga Swamy, Naveen Sivanna, Anand Tamatam and Farhath Khanum}

Biochemistry and Nutrition Discipline, Defence Food Research Laboratory, Mysore-570011, India

Corresponding author: Mahadevappa Siddalinga Swamy, PhD, Department of Biochemistry and Nutrition, Defence Food Research Laboratory, Mysore-570011, India.

Telephone: (911)-821-247-3290, Fax: +91-821-2473468

Submission date: October 17, 2011; Acceptance date: November 29, 2011; Publication date: November 30, 2011

\section{$\underline{\text { Abstract }}$}

\section{Background:}

Increased physical activities elevate reactive oxygen species (ROS) leading to dysfunction and integrity of cells thus inducing oxidative stress which intern may affect overall physical performance. Polyphenols are well known for their excellent antioxidant potency. In this study, the effect of selected polyphenols with established health benefits viz., catachin, chlorogenic acid, ellagic acid and quercetin was investigated with respect to swimming performance in rats.

Methods: The animals were force fed with aqueous mixture of polyphenols at $25 \mathrm{mg} / \mathrm{rat} / \mathrm{day}$ and subjected to swimming exercise until exhaustion.

\section{Results:}

Rats fed with poly phenols showed a significant increase in swimming time, and the activities of Lactic dehydrogenase (LDH) and creatine pyruvic kinase (CPK) were lowered. Polyphenols increased the concentration of Adenosine triphosphate (ATP), glycogen in muscle lowered the activities of and. Polyphenols increased the concentration of Adenosine triphosphate (ATP) and glycogen in muscle and reduced MDA levels in the liver, muscle and blood but increased DNA and RNA concentration in muscle.

Conclusion: The results clearly demonstrated combination of polyphenols used enhanced the swimming performance of the rats. 
Keywords: Polyphenols, Exercise capacity, ROS, ATP, Catachin, Chlorogenic acid, Ellagic acid and Quercetin.

Clinical trial registration number is 28/1999/CPCSEA dt. 11/3/1999

\section{Background}

Our earlier studies have clearly established that Polyphenolic extracts of pomegranate peel and green tea enhanced the swimming time of rats. However, there may be some other bioactive compounds present in the extract that might have exerted synergistic effects in enhancing the swimming time. Studies were carried out with polyphenolic combinations that are present in peel of pomegranate and green tea to rule out the synergistic effects of bioactive compounds other than polyphenols in increasing the swimming capacity of rats.

\section{INTRODUCTION}

Anti-fatigue agents are essential to enhance the physical performance in persons engaged in heavy manual work, sports personnel, or soldiers who will be performing physical work continuously. [1-2]. Depleted energy and micro nutrients need to be replaced avoiding a long process of digestion and absorption [3-4]. In addition, continuous and severe exercise leads to increased oxidative stress liberating the excess reactive oxygen species (ROS) [5-8]. Under these conditions endogenous antioxidants may not coupe up with the excessive formation of free radicals and should be supplemented with an antioxidant enriched diet [9-10]. These antioxidants by scavenging the radicals inhibit the cell and its components damaging and assisting smooth and normal function [11-13]. In our earlier studies performance enhancing properties of polyphenols extracted from pomegranate peel and green tea were demonstrated in animals exposed to force swimming test [14-15]. Feeding polyphenol extract from the peel and green tea increased swimming time, glycogen in liver and muscle, concentration of adenosine triphosphate (ATP) in muscle and reduced lipid peroxidation and lactic acid levels in tissues. However, both of the extracts may have other extracted bioactive compounds with synergistic effects for enhancing physical endurance. In the present study the animals were fed with the combination of polyphenols with established health benefits namely, Catachin (cardio protective, cancer prevention) [16-19], Chlorogenic acid and Ellagic acid (cancer inhibition) [16-17,20], Quercetin (cardio protective properties) [17], for evaluating for their physical endurance properties. These polyphenols are also present in pomegranate peel and green tea [14-15].

\section{MATERIALS AND METHODS}

\section{Materials:}

Polyphenols (PP) namely catachin, chlorogenic acid, Ellagic acid and Quercetin purchased from Sigma-Aldrich, USA, were mixed in equal quantities and made into an aqueous solution and were force fed to rats at the same concentration as followed in our earlier experiments $(25$ $\mathrm{mg} / \mathrm{rat} / \mathrm{day}$ ). Other chemicals used were of analytical grade purchased from M/s Merck, Germany and M/s SRL, Mumbai, India. 


\section{Animal Treatment:}

Animal experiments were carried out as per the guidelines of Institutional Animal Ethics Committee. Twenty four male albino rats of body wt 120-130 g were selected from the stock colony of this institution based on uniform food intake and body weight gain, placed individually in SS cages, exposed to 12 hours dark and light cycle and maintained at $27 \pm 2{ }^{\circ} \mathrm{C}$ with free access to drinking water and a synthetic diet (15\% casein protein, $10 \%$ fat from peanut oil with recommended levels of minerals and vitamins). These animals were divided into four groups of six rats, group I sedentary control; group II sedentary control but supplemented with PP, group III was force fed with only water group IV was force fed with $25 \mathrm{mg}$ PP emulsion /rat/day, daily in the morning at $11 \mathrm{AM}$ after fasting the rats for 2 hours (the diet cups were removed at 9 AM), for 21 days and subjected to swimming exercise daily until exhaustion (defined as animal fail to swim), from day 22 onward. On day 28, group III and IV rats were sacrificed immediately after swimming by cervical dislocations along with other groups.

\section{Biochemical Assays:}

The liver tissue was washed with ice-cold saline. One hundred milligrams of tissue was immediately digested in $30 \% \mathrm{KOH}$ for glycogen estimation [28]. Total fat from muscle was extracted and analyzed according to Folch et al., [29]. The extent of lipid peroxidation was determined by assaying malondialdehyde (MDA) formation according to the method of Sinnhuber et al., [30]. The total LDH content in serum samples was estimated following the method of Bach et al [31] with minor modifications. Serum CPK was estimated according to Laurence [32]. ATP was determined by HPLC based on the method developed by Ryder [33] and Agustini et al., [34]. The samples were minced with scissors; then, $0.5 \mathrm{~g}$ of the sample was homogenized with $2 \mathrm{ml}$ of chilled 5\% perchloric acid. The homogenate was centrifuged at 2000 $\mathrm{g}$ for $10 \mathrm{~min}$, a part of the supernatant $(0.5 \mathrm{ml})$ were neutralized with $1.0 \mathrm{M} \mathrm{KOH}(0.2 \mathrm{ml})$ and $0.3 \mathrm{ml}$ of distilled water was added. The neutralized mixture was centrifuged again and the supernatant was filtered through a $0.22 \mu \mathrm{m}$ filter for subsequent analysis. Separation of ATP was carried out on a reverse-phase $\mathrm{C} 18$ column, $50 \mathrm{mM}$ sodium di-hydrogen phosphate $(\mathrm{pH} 4.0)$ was used as the mobile phase at a flow rate of $1 \mathrm{ml} / \mathrm{min}$. The separation was monitored at $254 \mathrm{~nm}$ for ATP compared to the standard retention time.

\section{Statistical analysis:}

Student's ' $t$ ' test was carried out for calculating purposes. The significance level was set at $\mathrm{p}<$ 0.05. The data presented in the figure and tables are the mean (median; SE).

\section{RESULTS AND DISCUSSION}

Polyphenols (PP) are known antioxidants due to the presence of several hydroxyl groups, they scavenge ROS/radicals by donating free electrons. Some of the polyphenols are reported to inhibit the progression of cancer, cardio vascular diseases and other chronic diseases cited earlier [16-20]. They are also known to inhibit cellular damage, modulate signal transduction, etc, [21]. Excessive radicals need to be neutralized to protect the cell membrane and its components for normal functioning. It has been shown that sustained elevated oxidative stress may hamper 
mitochondrial function impairing the synthesis and utilization energy rich molecules namely Adenosine triphosphate (ATP) [21]. Oxidative phosphorylation requires intact mitochondrial membrane. Thus free diffusion of electrons may affect the discharge of the electrochemical gradient that dissipate the electrochemical gradient, allowing electron transport from NADH to succinate oxidation to continue but inhibits ATP synthesis resulting in uncoupled electron transport from oxidative phosphorylation. This may occur under stress conditions, causing less ATP synthesis [2], negatively affecting the overall performance.

On the other hand oxygen needs to be transported into various tissues via oxygen rich hemoglobin $(\mathrm{Hb})$ for better utilization of available nutrients while deriving the required energy. Stress releases negatively charged electrons, which may bound to positively charged groups present in $\mathrm{Hb}$ disrupting the oxygen supply and decreasing the efficiency of energy deriving processes since aerobic ATP production is far more efficient than anaerobic ATP production [22$24]$.

In anaerobic condition: $\mathrm{C}_{6} \mathrm{H}_{12} \mathrm{O}_{6}+2 \mathrm{ADP}+2 \mathrm{Pi} \rightarrow 2$ lactate $+2 \mathrm{H}^{+}+2 \mathrm{H}_{2} \mathrm{O}+2 \mathrm{ATP}$ Whereas in aerobic condition: $\mathrm{C}_{6} \mathrm{H}_{12} \mathrm{O}_{6}+38 \mathrm{ADP}+38 \mathrm{Pi}+6 \mathrm{O}_{2} \rightarrow 6 \mathrm{CO}_{2}+44 \mathrm{H}_{2} \mathrm{O}+38 \mathrm{ATP}$ Thus aerobic metabolism is 19 times more efficient than anaerobic glycolysis in producing ATP. These observations suggest antioxidants assist in the undisrupted oxygen supply that creates the aerobic environment, and besides inhibiting cell damage, they may enhance the overall physical performance under the stress condition [22-24].

In this study increased lipid peroxidation was observed in the liver (124\%) muscle $(109 \%)$, brain $(54 \%)$ and blood (86\%) in group-III animals (Table-1).

Table 1. Effect of PP on lipid peroxidation in muscle, liver, brain and lipid content in muscle and liver

\begin{tabular}{|l|l|l|l|l|l|}
\hline Groups & $\begin{array}{l}\text { Liver MDA } \\
(\boldsymbol{\mu m o l e s})\end{array}$ & $\begin{array}{l}\text { Muscle MDA } \\
(\boldsymbol{\mu m o l e s})\end{array}$ & $\begin{array}{l}\text { Brain MDA } \\
(\boldsymbol{\mu m o l e s})\end{array}$ & $\begin{array}{l}\text { Muscle total } \\
\mathbf{f a t}(\mathrm{g})\end{array}$ & $\begin{array}{l}\text { Liver total fat } \\
(\mathrm{g})\end{array}$ \\
\hline Group I & $0.41 \pm 0.06$ & $0.61 \pm 0.05$ & $0.33 \pm 0.04$ & $0.39 \pm 0.08$ & $0.77 \pm 0.09$ \\
Group II & $0.33 \pm 0.05$ & $0.66 \pm 0.05$ & $0.23 \pm 0.03$ & $0.41 \pm 0.06$ & $0.84 \pm 0.05$ \\
Group III & $1.04 \pm 0.11^{*}$ & $1.38 \pm 0.05^{*}$ & $0.37 \pm 0.04$ & $0.17 \pm 0.06^{*}$ & $0.38 \pm 0.05^{*}$ \\
Group IV & $0.50 \pm 0.09^{* *}$ & $0.40 \pm 0.77^{* *}$ & $0.36 \pm 0.06$ & $0.24 \pm 0.05^{* *}$ & $0.54 \pm 0.03^{*}$ \\
\hline
\end{tabular}

Values \pm SD for 6 rats

Values bearing different superscript are significantly different at $\mathrm{p}<0.05$.

Lipid peroxidation releases radicals damaging the cell membrane and mitochondria [25-26]. Elevated levels of malonaldehyde (MDA) a lipid peroxidative product have been reported during 
severe exercise [5-8]. Mitochondrial damage may lead to the anaerobic metabolism of carbohydrates, the preferred energy source being fat, is supported by the increased activity of LDH (Table- 2).

Table 2. Effect of PP on serum CPK, LDH activity and lipid peroxidation product

\begin{tabular}{|l|l|l|l|}
\hline Groups & CPK (IU / dI) & LDH (IU /dI) & MDA (n Moles/dI) \\
\hline Group I & $220.9 \pm 25.8$ & $12.96 \pm 1.58$ & $48.4 \pm 4.3$ \\
Group III & $236.7 \pm 29.6$ & $14.23 \pm 1.77$ & $46.1 \pm 5.3$ \\
Group IV & $524.7 \pm 40.8^{*}$ & $39.46 \pm 2.94^{*}$ & $96.8 \pm 7.4^{*}$ \\
& $328.5 \pm 28.4^{* *}$ & $22.43 \pm 3.62^{* *}$ & $67.6 \pm 5.8^{* *}$ \\
\hline
\end{tabular}

Values \pm SD for 6 rats

Values bearing different superscript are significantly different at $p<0.05$.

It has been reported that elevated LDH activity increases lactic acid concentration in blood, reducing physical endurance [2,8]. Increased lactic dehydrogenase activity concentration may also indicate reduction in ATP synthesis due to created anaerobic conditions partially inhibiting pyruvic acid pathway and citric acid cycle for more ATP synthesis. The decreased ATP concentration (group-III) observed in this study support the cited literature (Table- 3 ).

Table 3. Effect of GTPP on glycogen, RNA, DNA and ATP levels in liver and muscle

\begin{tabular}{|l|l|l|l|l|l|}
\hline Groups & $\begin{array}{l}\text { Liver Glycogen } \\
(\mathbf{m g} / \mathbf{g})\end{array}$ & $\begin{array}{l}\text { Muscle Glycogen } \\
(\mathbf{m g} / \mathbf{g})\end{array}$ & $\begin{array}{l}\text { Muscle DNA } \\
(\mathbf{m g} / \mathbf{g})\end{array}$ & $\begin{array}{l}\text { Muscle RNA } \\
(\mathbf{m g} / \mathbf{g})\end{array}$ & $\begin{array}{l}\text { Muscle } \\
\text { ATP } \\
(\mathbf{p p m})\end{array}$ \\
\hline Control & $60.4 \pm 8.3$ & $22.63 \pm 1.84$ & $0.64 \pm 0.08$ & $2.74 \pm 0.33$ & $278 \pm 43$ \\
PP & $65.3 \pm 7.2$ & $24.24 \pm 1.52$ & $0.57 \pm 0.09$ & $3.04 \pm 0.28$ & $264 \pm 33$ \\
Exercise & $27.2 \pm 3.8^{*}$ & $13.57 \pm 0.79^{*}$ & $0.38 \pm 0.05^{*}$ & $2.06 \pm 0.17^{*}$ & $694 \pm 56^{*}$ \\
PP + Exercise & $48.4 \pm 6.2^{* *}$ & $18.18 \pm 0.58^{* *}$ & $0.57 \pm 0.08^{* *}$ & $3.04 \pm 0.21^{* *}$ & $988 \pm 88^{* *}$ \\
\hline
\end{tabular}

Values \pm SD for 6 rats

Values bearing different superscript are significantly different at $\mathrm{p}<0.05$. 
Stored glycogen in the tissues is the primary source of energy during exercise or strenuous manual work since muscle cannot mobilize fat as rapidly as glycogen and fatty acids cannot be metabolized anaerobically [22]. In addition, blood glucose levels needs to be maintained as much as possible through glycogen hydrolysis, since fatty acids cannot be converted into glucose in animals. The rate of hydrolysis of glycogen affects the oxygen affinity of hemoglobin. Thus, affinity to oxygen may decrease under enhanced glycogen hydrolysis and may also negatively affect physical performance. Muscle glycogen phosphorylase is activated by adenosine monophophate (AMP) a break down product of ATP. The increased glycogenolysis observed in this study in the animals in group III indicates the enhanced utilization of ATP molecules yielding more of AMP + ip stimulating further hydrolysis of glycogen. This may be the proper explanation for why there is less glycogen content in the muscle and liver of the group-III animals (Table-3) [22].

However, muscle and liver fat decreased to the same extent in both the groups- III and IV suggests the lesser role of polyphenols (Table-1) in fat metabolism in relation to utilization for deriving energy. Fat content in the muscle and liver was reduced by $57 \%$ and $21 \%$. The increased fat utilization in muscle could be due to more involvement of the tissue during severe swimming exercise.

Muscle cells have a high ATP turnover with free energy reservoirs, these factions regenerate ATP rapidly [26], the reaction proceeds with net synthesis of phosphocreatine, whereas with high metabolic activity with low ATP levels, the equilibrium shifts yields a net synthesis of ATP. Phosphocreatine acts as an ATP buffer in the cell containing creatine phosphokinase (CPK). In this study CPK activity was high in group-III animals suggesting low ATP concentration, or a decreased efficiency in the utilization of energy, or a decrease synthesis of ATP related to the elevated generation of free radicals in (Table-3). A significant decrease in DNA and RNA concentration in group-III may also be one of the possible reasons for decreased physical efficiency since muscle protein plays a vital role during strenuous and continuous work. Swimming time decreased by $119 \%$ in group-III (Table-4) which could be due to the various factors mentioned above.

Table 4. Effect of PP on swimming time (minutes)

\begin{tabular}{|l|l|l|l|l|l|l|l|}
\hline Groups & Day 1 & Day 2 & Day 3 & Day 4 & Day 5 & Day 6 & Day7 \\
\hline Group 3 & $12.4 \pm 4.2$ & $15.7 \pm 1.8$ & $19.4 \pm 2.9$ & $24.8 \pm 3.1$ & $26.1 \pm 2.6$ & $29.2 \pm 3.4$ & $32.1 \pm 1.8$ \\
Group 4 & $18.6 \pm 3.7$ & $23.5 \pm 2.8^{*}$ & $31.8 \pm 2.4^{*}$ & $43.6 \pm 2.1^{*}$ & $55.3 \pm 6.1^{*}$ & $64.5 \pm 3.3^{*}$ & $70.3 \pm 3.8^{*}$ \\
& & & & & & & \\
\hline
\end{tabular}

Values \pm SD for 6 rats

Values bearing different superscript are significantly different at $\mathrm{p}<0.05$. 
A significant increase in the swimming time was observed in group-IV animals which were forced fed with polyphenol (70 minutes in group-IV and 32 minutes in group-III (Table-4). Swimming time gradually increased in both group-III and IV from day 2 onward and remained significant until day 7. The increase in swimming time in both of the groups may be attributed to the learning process of animals. The increased swimming time observed could be due to the decreased lipid peroxidative products in liver, muscle and blood that has reduced invariably the formation of reactive oxygen species, or free radicals might have prevented cellular/mitochondrial damage maintaining the normal function of cells. Intact mitochondria maintained an aerobic environment for maximum energy formation and utilization. High ATP concentration observed in muscle tissue support the statement made (Table-3). Reduced ATP hydrolysis in this group slowed down the glycogenolysis thus higher glycogen content was found in liver and muscle tissues (Table-3). Reduction in LDH and CPK activity clearly demonstrate aerobic environment that leads to a higher energy formation and utilization to enhance swimming time (Table-4). Reduced lipid peroxidative products in the tissues (Table 1 and 2) may also contribute positively in transporting oxygen to tissues via oxygen rich hemoglobin [22]. In addition DNA and RNA molecules in muscle were intact (Table-3) indicating a wellmaintained protein metabolism that may also assist in increasing in the swimming time (Table4). However, no change in any of the analyzed parameters was observed in group-I and II, suggesting that antioxidants may not have a role in improving the antioxidant status in tissues under normal condition.

Feeding polyphenols had not affected the food intake or body weight gain in any of the four groups, and the average food intake and weight gain was not significantly different among the groups, it was $18.1 \pm 0.6 \mathrm{~g} /$ day and $5.1 \pm 0.4 \mathrm{~g} /$ day (Figure- 1 and 2).

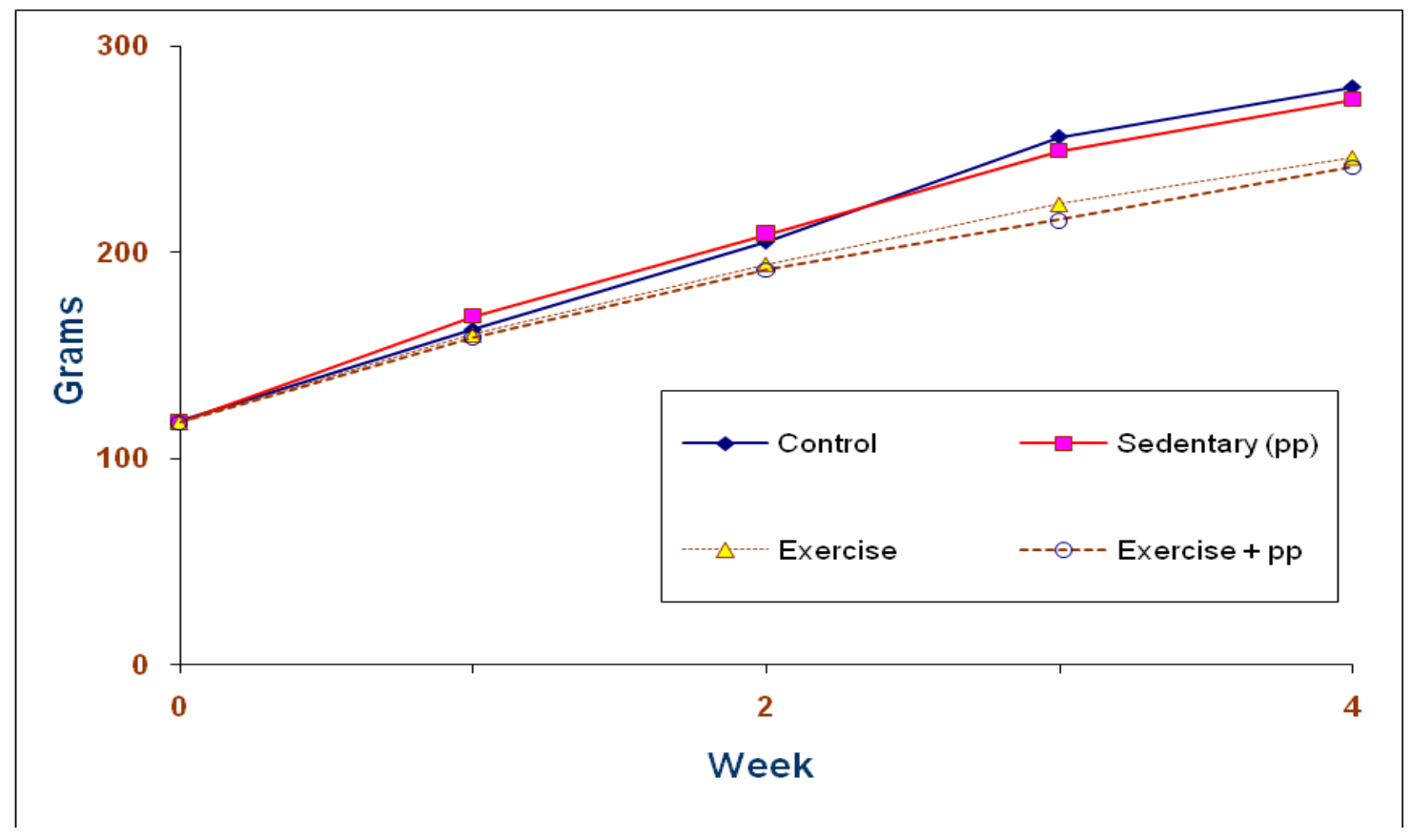

Figure 1: Effect of polyphenols on weight gain of rats 


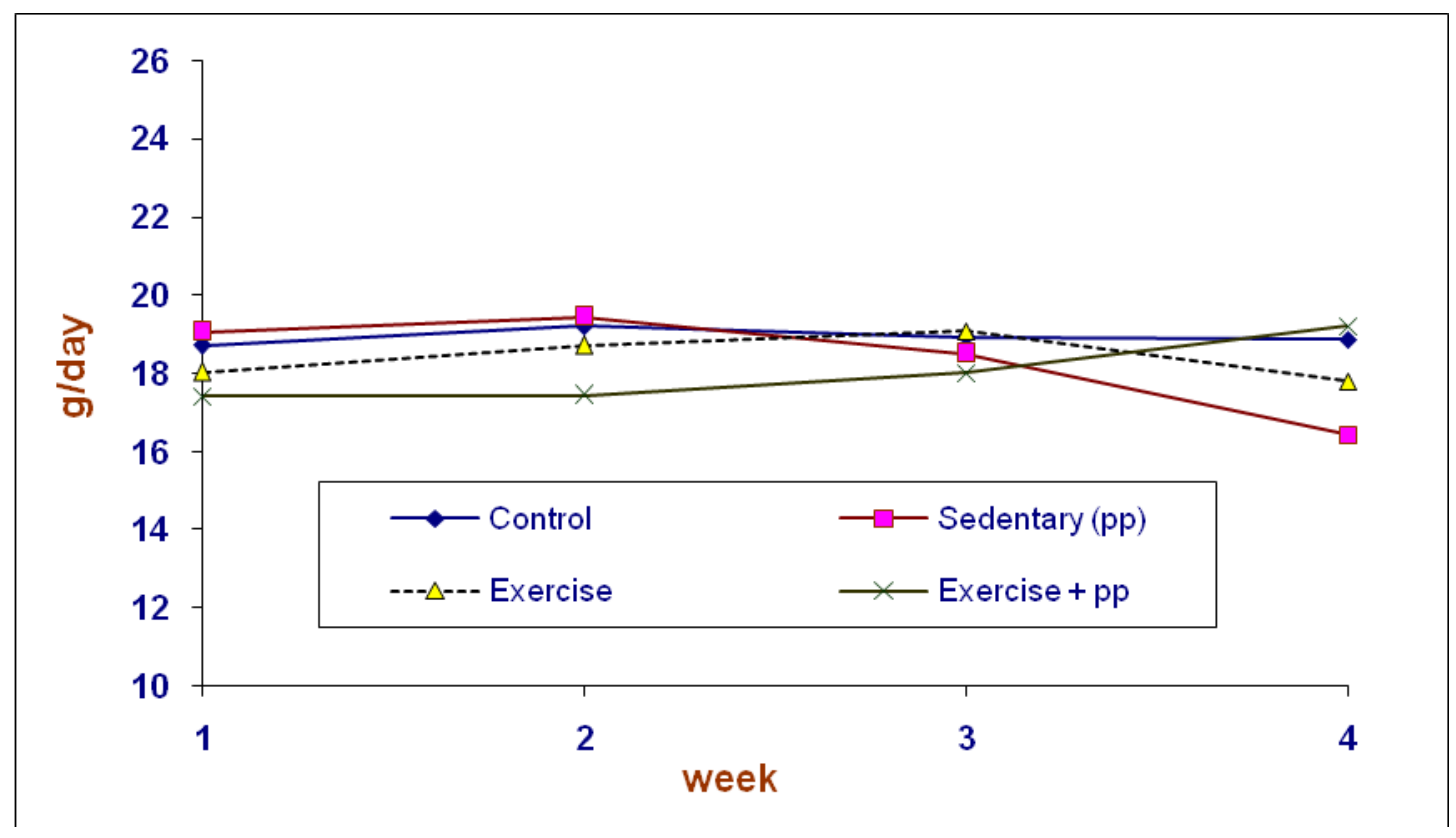

Figure 2: Effect of polyphenols on Food intake of rats

\section{CONCLUSIONS:}

In the present study the antioxidant, and enhancement of swimming capacity by synthetic polyphenolic combination, namely catechin, chlorogenic acid, ellagic acid, and quercetin, it was clearly established that the enzyme activities ( $\mathrm{LDH}, \mathrm{CPK}$ ), were reduced and the levels of lipid peroxidation (MDA), were decreased but there was increased ATP production glycogen contents in both liver and muscle, and PP also increased DNA and RNA content in the muscle tissue, enhancing the swimmibng capacity.

Abbreviations: Reactive Oxygen Species (ROS), Adenosine Triphosphate (ATP), Polyphenols (PP) , Adenosine Triphosphate (ATP), Hemoglobin (Hb), Malonaldehyde (MDA), Lactate Dehydrogenase (LDH), creatine phosphokinase (CPK).

\section{Competing interests:}

The authors declare that they have no competing interests.

\section{Authors' Contributions:}

M. Siddalingaswamy, M.Sc, $\mathrm{PhD}$, has contributed in planning the protocol supervising the study and manuscript preparation. Naveen. S, M.Sc, Ph.D, performed all of the analytical work. Anand. T, M.Sc, Ph.D, assisted in planning the protocol and in preparing the manuscript. Farhath Khanum, M.Sc, Ph.D, has supervised overall experimental work.

\section{Acknowledgements and Funding}

This study was supported by DRDO grant. We thank Dr. AS Bawa, Director, DFRL, Mysore, India, for his constant support and encouragement. 


\section{REFERENCES:}

1. Gandevia SC. Some central and peripheral factors affecting human motoneuronal output in neuromuscular fatigue. Sports medicine (Auckland, N.Z) 1992; 13: 93-98.

2. McMahon, Thomas A. Muscles; Reflexes. Locomotion. Princeton University Press. 1984; pp. 37-51.

3. Akova B, Sürmen Gür E, Gür H, Dirican M, Sarandöl E, Kücükoglu S. Exercise induced oxidative stress and muscle performance in healthy women: role of vitamin E supplementation and endogenous oestradiol. Eur J Appl Physiol 2001; 84: 141-147.

4. Urso ML, Clarkson PM. Oxidative stress, exercise, and antioxidant supplementation. Toxicol 2003; 189: 41-54.

5. Hagberg M. "Muscular endurance and surface electromyogram in isometric and dynamic exercise". J Appl Physiol Resp Environ Ex Physiol 1981; 51: 1-7.

6. Lebuffe G, Schumacker PT, Shao ZH, Anderson T, Iwase H, Vanden Hoek TL. Reactive oxygen and nitrogen species trigger early preconditioning: relationship to mitochondrial KATP channel. Am J Physiol Heart Circ Physiol 2003; 284: H299-H308.

7. Newcomer BR, Sirikul B, Hunter GR, Larson-Meyer E, Bamman M. Exercise over-stress and maximal muscle oxidative metabolism: a 31P magnetic resonance spectroscopy case report. $\mathrm{Br} \mathrm{J}$ Sport Med 2005; 39: 302-6.

8. Bangsbo J, Graham TE, Johansen L, Strange S, Christensen C, Saltin B. Elevated muscle acidity and energy production during exhaustive exercise in man. Am J Physiol Regulat Integr Comp Physiol 1992; 263: R881-R899.

9. Mianiati E, Colir R, Alberti Fidanza A. Studies on total diet in the Perugia area for monitoring food components and contaminants. IV. Total polyphenols and tannins content in foods mostly consumed. Rivista-di-Scienza-dell'Alimentazione 1994; 23: 13-19.

10. Ahmed S, Rahman A, Alam A, Saleem M, Athar M, Sultana S. Evaluation of the efficacy of Lawsonia alba in the alleviation of carbon tetrachloride-induced oxidative stress. J Ethnopharmacol 2000; 69: 157-164.

11. Kulkarni AP, Aradhya SM, Divakar S. Isolation and identification of a radical scavenging antioxidant-punicalagin from pith and carpellary membrane of pomegranate fruit. F Chem 2004; 87: 551-557.

12. Anon. Functional aspects of blueberries. Food-Marketing-\&-Technol 2003; 17: 14-15.

13. Campbell JK, Canene Adams K, Lindshield BL, Boileau TWM, Clinton SK, Erdman JW. Jr: Tomato phytochemicals and prostate cancer risk. J Nutr 2004; 134: 3486S-3492S.

14. Swamy MSL, Naveen $S$ and Farhath Khanum. Antifatigue mechanism of green tea polyphenols in rat subjected to forced swimming test. Int J Adv Pharm Res 2011; 2: 133-143.

15. Swamy MSL, Naveen $\mathrm{S}$ and Farhath Khanum. Anti-fatigue effects of polyphenols from pomegranate peel. Int J Integrat Biol 2011; 11: 69-72.

16. Stavric B. Role of chemopreventers in the human diet. Clin Biochem J Nutr 1994; 27: 319-327.

17. Stavric B. Role of chemopreventers in the human diet. Clin Bioch J Nutr 1994; 122: 2161-2166.

18. Herman C, Adlercreutz T, Goldin BR, Gorback SL, Hockerstedt KA, Watanabe S, Hamalainen EK, Markkanene MH, Makela TH, Wahala KT, Hase TA, Fotsis T. Soybean phytoestrogen intake and cancer risk. J Nutr 1995; 125: 757S-770S. 
19. Chan MMY, Ho, C.T., Huang, H.I. Effects of three dietary phytochemicals from Tea, Rosemary, and Turmeric on inflammation induced nitrite production. Cancer Lett 1995; 96: 23-29.

20. Stoner GD, Mukhtar H. Polyphenols as cancer chemopreventive agents. J Biochem Suppl 1995; 22: 169-180.

21. Shivanandappa $\mathrm{T}$ and Krishna Kumari. Histochemical and biochemical changes in rats fed dietary benzene hexachloride. Ind J Exp Biol 1981; 19: 1162-1168.

22. Lebuffe G, Schumacker PT. Reactive oxygen and nitrogen species trigger early preconditioning: relationship to mitochondrial KATP channel. Am J Physiol Heart Circ Physiol 2003; 284: H299H308.

23. Tran TK, Sailasuta N, Kreutzer U, Hurd R, Chung Y, Mole P, Kuno S, Jue T. Comparative analysis of NMR and NIRS measurements of intracellular PO2 in human skeletal muscle. Am J Physiol Reg Integr Comp Physiol 1999; 276: R1682-R1690.

24. Curtin NA, Woledge RC. Energy changes and muscular contraction. Physiol Rev 1978; 58: 69061.

25. Nicholls DG, Ferguson SJ. Bioenergetics 2. In: Textbook of Biochemistry. New York: Academic, 1992.

26. Panda K, Chattopadhyay R. Vitamin C prevents cigarette smoke induced oxidative damage of proteins and increased proteolysis. Fr Rad Biol Med 1999; 27: 1064-1079.

27. Pignatelli B, Li CQ, Boffetta P. Nitrated and oxidized plasma proteins in smokers and lung cancer patients. Can Res 2001; 61: 778-784.

28. Dreiling CE, Brown DE, Casale L, Kelly L. Muscle glycogen: Comparison of iodine binding and enzyme digestion assays and application to meat samples. Meat Sci 1987; 20: 167-177.

29. Folch J, Lees M, Stanley GHS. A simple method for the isolation and purification of total lipides from animal tissues. J Biol Chem 1957; 226: 497-509.

30. Sinnhuber RO, Yu TC, Yu TC. Characterization of the red pigment formed in the thiobarbituric acid determination of oxidative rancidity. Food Res 1958; 23: 626-630.

31. Bach MK, Brashler JR, Petzold EN, Sanders ME. Superoxide production by human eosinophils can be inhibited in an agonistselective manner. J Immunol Meth 1991; 142: 243.

32. Laurence AS. Serum myoglobin and creatine kinase following surgery. Br J Anaesth 2000; 84: 763-6.

33. Ryder JM. Determination of adenosine triphosphate and its breakdown products in fish muscle by high performance liquid chromatography. J Agri Food Chem 1985; 33: 678-680.

34. Agustini TW, Suzuki T, Hagiwara T, Ishizaki S, Tanaka M, Takai R. Change of K value and water state of yellow tuna Thunnus albacares meat stored in a wide temperature range $\left(2^{\circ}-\right.$ 84oC). Fish Sci 2001; 67: 306-313. 